\title{
Venoarterial extracorporeal membrane oxygenation support for neonatal and pediatric refractory septic shock
}

\author{
Jerome Rambaud, Isabelle Guellec, Pierre-Louis Léger, Sylvain Renolleau, Julia Guilbert
}

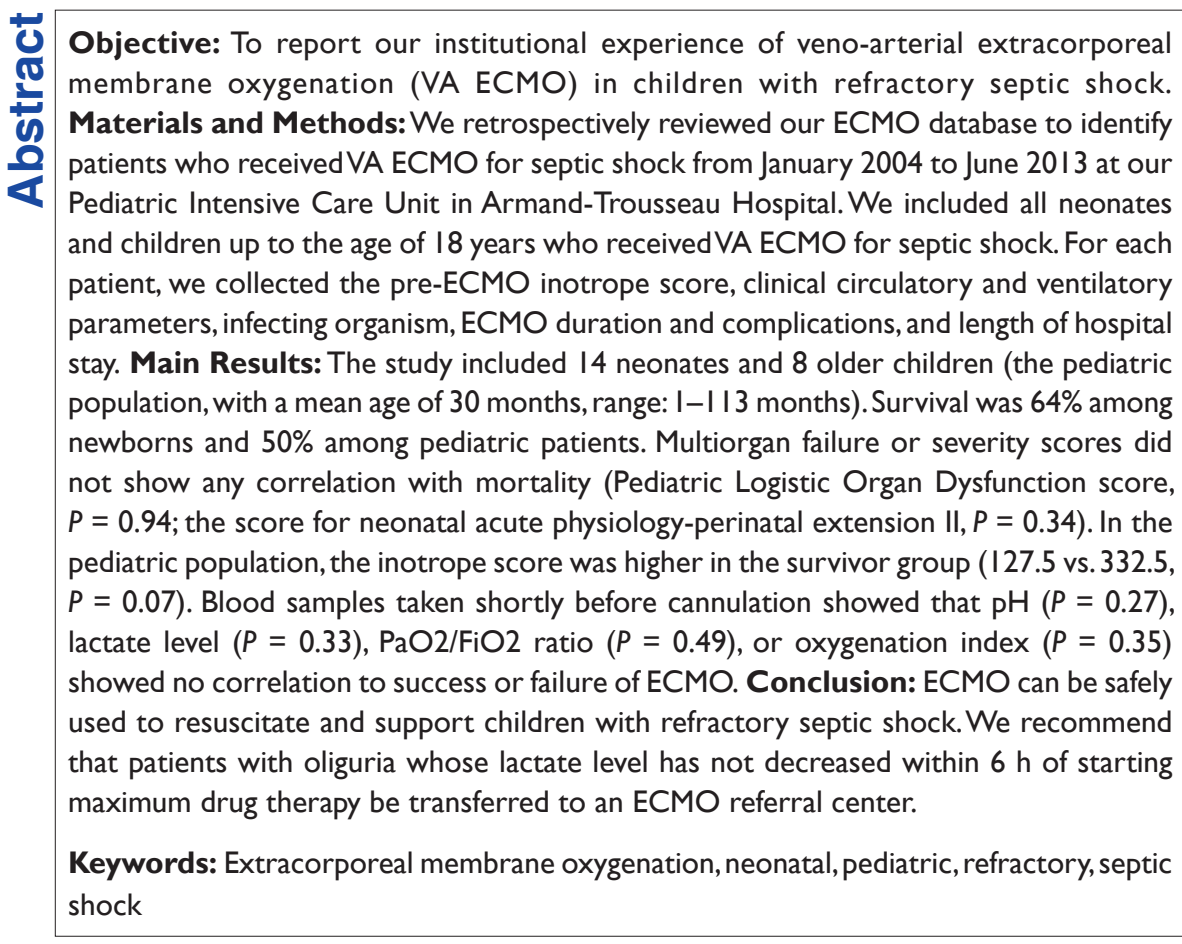

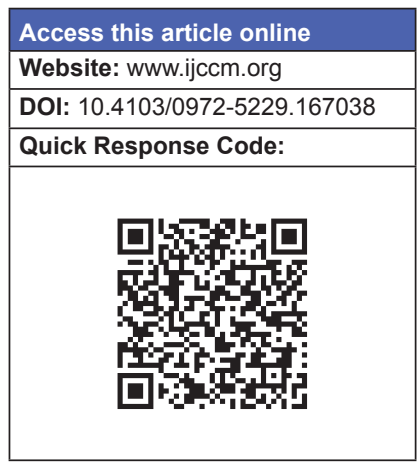

\section{Introduction}

Septic shock is an important cause of mortality in Pediatric Intensive Care Units (PICUs) and one of the leading causes of childhood mortality worldwide. In developed countries, mortality from pediatric septic shock ranges from $15 \%$ to $50 \% .^{[1-4]}$ The American College of Critical Care Medicine has published guidelines to assist clinicians caring for children with septic shock. ${ }^{[5]}$

From:

Pediatric and Neonatal Intensive Care Unit, Armand-Trousseau Hospital,

Paris, France

\section{Correspondence:}

Dr. Jerome Rambaud, Pediatric and Neonatal Intensive Care Unit, Armand-Trousseau Hospital, Paris, France.

E-mail: jerome.rambaud@trs.aphp.fr
These recommendations were reinforced by a section on treatment of children in the first Surviving Sepsis campaign guidelines in 2004, and regular updates thereafter. ${ }^{[6-8]}$ It is recommended that venoarterial extracorporeal membrane oxygenation (VA ECMO) be considered for neonates or children with circulatory

This is an open access article distributed under the terms of the Creative Commons Attribution-NonCommercial-ShareAlike 3.0 License, which allows others to remix, tweak, and build upon the work non-commercially, as long as the author is credited and the new creations are licensed under the identical terms.

For reprints contact: reprints@medknow.com

How to cite this article: Rambaud J, Guellec I, Léger PL, Renolleau S, Guilbert J. Venoarterial extracorporeal membrane oxygenation support for neonatal and pediatric refractory septic shock. Indian J Crit Care Med 2015;19:600-5. 
collapse unresponsive to all conventional treatment. ${ }^{[8]}$ Overall, survival of septic patients supported with ECMO is $73 \%$ for neonates and $39 \%$ for older children. ${ }^{[9]}$ Compared with these rates for conventional ECMO, the outcome for children appears better in central (also called atrio-aortic) ECMO, for which a 74\% pediatric survival rate has been reported. ${ }^{[10]}$

The aim of this study was to describe our experience in the management of refractory septic shock treated with conventional ECMO.

\section{Materials and Methods}

\section{Patients}

This single-center retrospective study of our ECMO database identified patients who received conventional VA ECMO for refractory septic shock from January 2004 to June 2013, in the Armand-Trousseau Hospital PICU, a conventional ECMO referral center.

Neonates and children up to 18 years old were included if they met the following inclusion criteria: VA ECMO for circulatory collapse after the failure of fluid resuscitation and inotrope therapy, clinical signs of infection, isolation of a bacterial microorganism, and a high lactate level.

Our protocol for VA ECMO excludes children with prolonged cardiac arrest $(>60 \mathrm{~min})$ or a severe irreversible neurological pathology such as cranial hemorrhage or flat electroencephalogram tracing and those with secondary septic shock who required ECMO primarily for respiratory failure.

\section{The institutional review board approved this study.}

\section{General management of septic shock}

Our practices follow the guidelines published by Dellinger et al. ${ }^{[11]}$ Children with severe septic shock admitted to our unit are given volume loading with colloid or crystalloid infusion before a vasoactive agent is started, generally dopamine in neonates and norepinephrine in children. Dobutamine is used if there is evidence of myocardial depression and low cardiac output. ECMO is instituted if shock persists, or cardiac arrest occurs.

\section{Application of extracorporeal membrane oxygenation}

VA ECMO is applied by trained vascular surgeons at bedside because hemodynamic instability makes it too dangerous to move the child. In neonates and children weighing less than $20 \mathrm{~kg}$, cannulas are placed in the jugular vein and the carotid artery. In larger children, a femoral artery cannula is also placed, with an additional catheter systematically inserted distally into the femoral artery to prevent leg ischemia.

The pumps used in this study were nonocclusive pumps with distensible tubing (A100, Sofracob ${ }^{\circledR}$ ) for newborns and centrifugal pumps (Rotaflow, Maquet ${ }^{\circledR}$ ) for pediatric patients.

The membrane oxygenators used were the MedosHilite800LT ${ }^{\circledR}$ and MaquetQuadrox-iDpediatric ${ }^{\circledR}$. The main difference between these two types of membrane oxygenators lies in their structure, their surface, and their cost. ${ }^{[12]}$

\section{Patient management during extracorporeal membrane oxygenation}

The pump is adjusted to obtain a blood flow of 100-150 cc/kg/min for neonates and 4-6 L/m2/min for children. Anticoagulation with intravenous unfractionated heparin is administered to maintain an activated partial thromboplastin time of twice normal. Weaning from ECMO is decided after hemodynamic parameters have remained normal for $12 \mathrm{~h}$, with minimal assistance.

\section{Data collected at Intensive Care Unit admission}

Before cannulation, we recorded the following information: Age, sex, infection site, microorganism identified, Pediatric Logistic Organ Dysfunction score (PELOD), ${ }^{[13]}$ pediatric index of mortality II (PIM II) score, score for neonatal acute physiology-perinatal extension II (SNAP, and SNAPPE for neonatal patients), ${ }^{[14]}$ time from PICU admission to cannulation, whether ECMO began during cardiopulmonary resuscitation, the pre-ECMO inotrope score, defined as dose of dobutamine $(\mu \mathrm{g} / \mathrm{kg} / \mathrm{min})+($ dose of epinephrine $[\mu \mathrm{g} / \mathrm{kg} / \mathrm{min}]+$ dose of norepinephrine $[\mu \mathrm{g} / \mathrm{kg} / \mathrm{min}] \times 100),{ }^{[15]}$ the $\mathrm{PaO}_{2} / \mathrm{FiO}_{2}$ ratio, ${ }^{[16]}$ blood gas analyses, blood lactate, urine output, leukocyte count, C-reactive protein (CRP), procalcitonin (PCT), positive end-expiratory pressure, indexed tidal volume, and oxygenation index.

The principal outcome variables were survival to PICU discharge, time to lactate normalization, and neurologic complications. Other outcomes included the need for renal replacement therapy, the number of units of packed red blood cells and platelets transfused, capillary leak syndrome, hemorrhagic complications, days on ECMO, and time on mechanical ventilation. 


\section{Statistics}

Continuous data were presented as means (standard deviation) for normally distributed variables or medians (inter-quartile-range) for skewed. A categorical variable was presented as proportions. We compared survivor and nonsurvivor population using Fisher's exact test or ANOVA tests, if appropriate. $P<0.05$ was considered as significant.

We used Stata 13 (StatCorp, College Station, Texas, USA) for analysis.

\section{Results}

\section{General population}

We compared survivors and nonsurvivors in the entire population and separately by age group (neonates and pediatric population). This population comprised 22 patients: 14 neonates and 8 children. Eight were girls and 14 boys.

Table 1 describes the patients' characteristics at the time of connection to the ECMO circuit and the cause of their septic shock. Among the neonates, the shock was due to Streptococcus B infection for $57 \%$ and to Escherichia coli in $36 \%$. The mean age of the pediatric population was 30 months (range: 1-113 months). All patients were intubated, ventilated and received inotropes before ECMO. Despite fluid and vasoactive drug administration, they had a progressive circulatory failure.

Two patients (9\%) had cardiac arrest and were receiving chest compressions during cannulation. Conventional ECMO was placed at a mean of $12( \pm 13.4)$ $\mathrm{h}$ after admission in our unit.

The overall survival rate was $59.1 \%$. Nine newborns survived to hospital discharge $(64 \%)$, and 4 pediatric patients (50\%). Survival was significantly better among the neonates $(P=0.02)$.

Survivors did not differ significantly from the patients who died for their inotrope score $(P=0.77)$, or for laboratory or ventilation data.

\section{Neonatal population}

\section{Preadmission and admission data}

Table 2 summarizes the clinical characteristics of the neonates before ECMO. The mean SNAPPE-II severity score on PICU admission was associated with a $15.8 \%$ risk of mortality $( \pm 17.4)$ and did not differ between those who did and did not survive. The average time
Table I: Infectious disease responsible for refractory septic shock

\begin{tabular}{ll}
\hline Patients & Bacterial microorganism \\
\hline Neonate I & P. aeruginosa \\
Neonate 2 & Streptococcus B \\
Neonate 3 & Streptococcus B \\
Neonate 4 & Streptococcus B \\
Neonate 5 & - \\
Neonate 6 & E. Coli \\
Neonate 7 & E. Coli \\
Neonate 8 & Streptococcus B \\
Neonate 9 & E. Coli \\
Neonate 10 & E. Coli \\
Neonate II & E. Coli \\
Neonate I2 & Streptococcus B \\
Neonate I3 & Streptococcus B \\
Neonate I4 & Streptococcus B \\
Pediatric I & Influenza HINI and S. pneumonia \\
Pediatric 2 & Enterobacter \\
Pediatric 3 & - \\
Pediatric 4 & - \\
Pediatric 5 & Streptococcus A \\
Pediatric 6 & Legionella \\
Pediatric 7 & Shigella \\
Pediatric 8 & E. Coli \\
\hline S. pneumonia: Streptococcus pneumonia; P. aeruginosa: Pseudomonas aeruginosa; &
\end{tabular}

E. Coli: Escherichia coli

Table 2: Neonatal circulatory and ventilatory data immediately before cannulation for extracorporeal membrane oxygenation

\begin{tabular}{|c|c|c|c|}
\hline Characteristics & Mean & Median & SD \\
\hline Gestational weeks & 39.3 & 40 & 2.09 \\
\hline Age (days) & 1.1 & 1 & 1.23 \\
\hline Weight (kg) & 3.3 & 3.4 & 0.45 \\
\hline SNAPPE II (risk of mortality \%) & 15.28 & 6.5 & 17.4 \\
\hline Inotrope score $(\mu \mathrm{g} / \mathrm{kg} / \mathrm{min})$ & I77. & 145 & 149.28 \\
\hline Mean arterial pressure $(\mathrm{mmHg})$ & 34 & 33 & 8.07 \\
\hline Mean pH (range) & 7.13 & 7.11 & 0.12 \\
\hline Blood lactate $(\mathrm{mmol} / \mathrm{L})$ & 7.94 & 6.88 & 4.92 \\
\hline Urine output (ml/kg/h) & 1.8 & 0.5 & 1.9 \\
\hline $\mathrm{C}$ reactive protein $(\mathrm{mg} / \mathrm{L})$ & 129.6 & 106.5 & 106.6 \\
\hline Tidal volume (ml/kg) & 8.56 & 8.5 & 1.57 \\
\hline $\operatorname{PEEP}\left(\mathrm{cm} \mathrm{H}_{2} \mathrm{O}\right)$ & 6 & 6 & 1.83 \\
\hline Mean airway pressure $\mathrm{cm} \mathrm{H}_{2} \mathrm{O}$ & 14 & 13 & 5.08 \\
\hline $\mathrm{PaO}_{2} / \mathrm{FiO}_{2}$ ratio & 72 & 42 & 13.55 \\
\hline Oxygenation index & 47 & 25 & 69.54 \\
\hline $\mathrm{PaCO}_{2}(\mathrm{mmHg})$ & 54 & 58 & 13.55 \\
\hline
\end{tabular}

SD: Standard deviation; PEEP: Positive end-expiratory pressure; SNAPPE II: Score for neonatal acute physiology-perinatal extension II

until cannulation after arrival in our unit was $9.3 \mathrm{~h}$ (range: 1-21).

The survivors did not differ significantly from nonsurvivors for multiorgan failure score $(P=0.33)$, inotrope score $(P=0.2)$, blood lactate level $(P=0.11)$, or $\mathrm{pH}(P=0.2)$

At PICU admission, 6 of the 14 neonates underwent Doppler echocardiography, with a mean left ventricular ejection fraction of $31.6 \%$ [range: 15-35]. Two patients had bradycardia during cannulation. 


\section{Postcannulation data}

The mean time on ECMO was 7.43 days (range: 1-17). The mean lactate at hour 6 (H6) was $7.26 \mathrm{mmol} / \mathrm{L}$ (range: 2.4-18) and at H24 5.28 (range 1.4-11); it did not differ significantly between survivors and nonsurvivors. Six neonates $(42 \%)$ had mechanical problems with the ECMO circuit. These included episodes of clotting in the circuit requiring circuitry changes, but no oxygenator pump failure or air in the circuit. One patient needed continuous hemofiltration. Of the remaining 5 deaths, 4 developed irreversible organ failure, and 3 died from failure of resuscitation while treatment was withdrawn for one. One patient was certified brain-dead.

\section{Consumption of blood products}

The average daily consumption of blood products was 0.22 units of packed red blood cells, 0.73 units of platelet concentrate, and 0.05 units of freshly active plasma. No significant difference was found between survivors and nonsurvivors for blood product consumption.

\section{Pediatric population}

\section{Preadmission and admission data}

Table 3 summarizes the clinical characteristics of the pediatric population before ECMO. At PICU admission, the mean PELOD score was $65.5 \%( \pm 37.5)$ and the mean PIM II score 75\% ( \pm 32.3$)$ and did not differ significantly between survivors and nonsurvivors $(P=0.9$ and 0.3 , respectively). The mean time until cannulation after arrival in our unit was $16.9 \mathrm{~h}( \pm 18.4$; range: $0.5-48)$. Two children (25\%) had had cardiac arrest and were receiving chest compressions immediately before cannulation. No significant difference was found between survivors and nonsurvivors regarding PELOD $(P=0.9)$, PIM II

Table 3: Pediatric circulatory and ventilatory data prior to extra-corporeal membrane oxygenation implantation

\begin{tabular}{|c|c|c|c|}
\hline Characteristics & Mean & Median & SD \\
\hline Age (months) & 30 & 15 & 37.5 \\
\hline Weight (kg) & II.I & 10.5 & 6.4 \\
\hline PIM II (pediatric index mortality) & 77.1 & 92.4 & 34.9 \\
\hline PELOD (risk of mortality \%) & 65.5 & 84 & 37.7 \\
\hline Inotrope score $(\mu \mathrm{g} / \mathrm{kg} / \mathrm{min})$ & 230 & 195 & 165 \\
\hline Mean arterial pressure $(\mathrm{mmHg})$ & 40 & 40 & 4.9 \\
\hline Mean pH (range) & 6.97 & 7 & 0.14 \\
\hline Blood lactate (mmol/L) & 5.2 & 5.3 & 3.5 \\
\hline Urine output (ml/kg/h) & 1.3 & 0.6 & 1.5 \\
\hline Protein C-reactive (mg/L) & 250.9 & 245.3 & 144.4 \\
\hline Tidal volume (ml/kg) & 7 & 7.9 & 1.4 \\
\hline $\operatorname{PEEP}\left(\mathrm{cm} \mathrm{H}_{2} \mathrm{O}\right)$ & 8 & 7 & 4.5 \\
\hline Mean airway pressure $\mathrm{cm} \mathrm{H}_{2} \mathrm{O}$ & 15 & 14 & 7.7 \\
\hline $\mathrm{PaO}_{2} / \mathrm{FiO}_{2}$ ratio & 89.2 & 75.5 & 45.1 \\
\hline Oxygenation index & 19 & 19.5 & 5.9 \\
\hline $\mathrm{PaCO}_{2}(\mathrm{mmHg})$ & 73 & 68 & 41.6 \\
\hline
\end{tabular}

PEEP: Positive end-expiratory pressure; PELOD: Pediatric logistic organ dysfunction; PIM: Pediatric index of mortality; SD: Standard deviation score $(P=0.2)$, or inotrope score $(P=0.07)$. The inotrope score was higher, but not quite statistically significant $(P=0.07)$, among the children who died than in survivors. The pre-cannulation blood test showed no significant differences between these two groups for blood lactate $(P=0.9), \mathrm{pH}(P=0.4), \mathrm{CRP}(P=0.1)$, or PCT $(P=0.2)$.

At PICU admission, seven of the eight children underwent Doppler echocardiography. Their mean left ventricular ejection fraction was $23.3 \%$ (range: $0-40$ ).

\section{Postcannulation data}

The mean time on ECMO was 5.9 days (range: 3-10). Mean lactate at H6 was $5.18 \mathrm{mmol} / \mathrm{L}$ (range; 1.4-10) and at H24 3.23 (range: 1.4-9.5); it did not differ significantly between survivors and nonsurvivors. Three children (37\%) had mechanical problems with the ECMO circuit, including episodes of circuit clotting requiring circuitry change, but no oxygenator pump failure or air in the circuit. Only one child (12\%) presented severe cerebral bleeding, and two children (25\%) had strokes. Three (37\%) required renal replacement therapy, for a mean duration of 16 days (range: 3-16) (no significant difference between survivors and nonsurvivors for renal replacement therapy, $P=0.4$ ). The mean duration of mechanical ventilation was 14 days (range; 4-31) and of PICU length of stay 17 days (range: 4-40). Six patients were weaned from ECMO (66\%), but 2 died a few days later, one after the onset of an intracranial infarction and cerebral hemorrhage and the other after the onset of acute respiratory distress syndrome onset. Two patients died during ECMO: One was certified brain dead; treatment for other was withdrawn after the development of irreversible organ failure.

\section{Consumption of blood products}

The average daily consumption of packed red blood cells was 0.3 units per day, of platelet concentrates 1.6 units daily, and freshly active plasma 0.1 units daily. This blood product consumption did not differ significantly between survivors and nonsurvivors.

\section{Discussion}

ECMO for refractory septic shock is recognized as a useful last-resort treatment for adults, ${ }^{[17]}$ neonates, and children. ${ }^{[10,17]}$ Survival is better in the neonatal than the pediatric population, for all diseases combined, as reported to the Extracorporeal Life Support Organization registry (ELSO). ${ }^{[18]}$

Survival in adults varies widely, from $74 \%$ in the study by Bréchot et al. to $15 \%$ in that by Huang et al. ${ }^{[17,21]}$ 
Older studies report that ECMO for septic shock was associated with a survival rate greater than $80 \%$ in newborns ${ }^{[19,20]}$ and $15 \%$ to $74 \%$ in older children. ${ }^{[10,21-23]}$ These rates are both lower in our study. Changes over time in treatment modes and in the population of patients receiving ECMO may explain these differences. ${ }^{[24]}$ The older studies do not report clinical or laboratory characteristics. ${ }^{[19]}$ In 2011, MacLaren et al. reported a 74\% survival rate in a series of 23 children with refractory septic shock treated with a new variant of VA ECMO that used central cannulation (through the right atrium and aorta). They called this central (or atrioaortic) ECMO ${ }^{[10]}$ Their preliminary data comparing the first 11 patients on central ECMO to historical controls suggested improved survival to hospital discharge in the group with central ECMO. ${ }^{[23,25]}$ Their 2011 results confirm this data. ${ }^{[10]}$ The patients in our study seemed to present more severe hemodynamic failure, with higher inotrope scores (230 vs. 82.2$)$ and lower $\mathrm{pH}$ (6.97 vs. 7.11) than in MaLaren's cohort. The level of multiorgan failure is difficult to analyze or compare in the absence of scoring systems such as PIM II and PELOD. Our pediatric patients had a high risk of mortality before ECMO. There is, unfortunately, no scoring system for multiorgan failure for neonates.

Nevertheless, our survival rate approximates that in MacLaren's first study ${ }^{[23]}$ in the children undergoing conventional ECMO (that is, with peripherally placed cannulas). It is difficult to judge the pertinence of central ECMO objective in refractory septic shock. MacLaren et al. ${ }^{[23]}$ compared this option to results from their historical cohort with conventional ECMO. Advances in ECMO technology between the two periods include aspects of biocompatibility, monitoring, and membrane lungs. ${ }^{[26]}$ Central ECMO is more invasive, and it is indicated only for left ventricular failure due to outflow obstruction. Our cohort included no patients with left ventricular failure during ECMO.

In our study, the inotrope score was higher in the children who died. This observation raises a recurring question: When can septic shock be considered refractory? The Surviving Sepsis campaign ${ }^{[8,11]}$ clearly defines the $1^{\text {st }} h$ of severe sepsis and septic shock but not the onset of refractory septic shock or any time period at which VA ECMO should begin. Effective lactate clearance during the first $6 \mathrm{~h}$ of septic shock is known to be a reliable indicator of better prognosis, and several studies have suggested that persistent lactate elevation is associated with high patient mortality and multiple organ damages. ${ }^{[27-30]}$ These studies provide a reasonable basis for using serial lactate laboratory tests to monitor for prognosis and therapeutic effectiveness in pediatric septic shock.

In 2009, Brierley et al..$^{[5]}$ defined early goals of therapy for septic shock but did not specify a time course at which VA ECMO is indicated for a refractory septic shock. There is currently no time period consensually used to define when septic shock becomes refractory. We suggest here that refractory septic shock be defined as the absence of lactate clearance. ${ }^{[31]}$ associated with oliguria $6 \mathrm{~h}$ after maximum drug therapy begins. We propose that neonates and children are meeting these criteria be transferred to a referral center for ECMO.

\section{Conclusion}

Extracorporeal membrane oxygenation can be safely used to resuscitate and support children with refractory septic shock. We propose to transfer to an ECMO referral center patients who have oliguria and no decrease of lactate level with oliguria within $6 \mathrm{~h}$ of maximum drug therapy.

\section{Financial support and sponsorship Nil.}

\section{Conflicts of interest}

There are no conflicts of interest.

\section{References}

1. Wolfler A, Silvani P, Musicco M, Antonelli M, Salvo I; Italian Pediatric Sepsis Study (SISPe) Group. The incidence of and mortality due to sepsis, severe sepsis and septic shock in Italian Pediatric Intensive Care Units: A prospective national survey. Intensive Care Med 2008;34:1690-7.

2. Watson RS, Carcillo JA. Scope and epidemiology of pediatric sepsis. Pediatr Crit Care Med 2005;6 3 Suppl: S3-5.

3. Shime N, Kawasaki T, Saito O, Akamine Y, Toda Y, Takeuchi M, et al. Incidence and risk factors for mortality in paediatric severe sepsis: Results from the national paediatric intensive care registry in Japan. Intensive Care Med 2012;38:1191-7.

4. Inwald DP, Tasker RC, Peters MJ, Nadel S; Paediatric Intensive Care Society Study Group (PICS-SG). Emergency management of children with severe sepsis in the United Kingdom: The results of the Paediatric Intensive Care Society sepsis audit. Arch Dis Child 2009;94:348-53.

5. Brierley J, Carcillo JA, Choong K, Cornell T, Decaen A, Deymann A, et al. Clinical practice parameters for hemodynamic support of pediatric and neonatal septic shock: 2007 update from the American College of Critical Care Medicine. Crit Care Med 2009;37:666-88.

6. Dellinger RP, Carlet JM, Masur H, Gerlach H, Calandra T, Cohen J, et al. Surviving Sepsis Campaign guidelines for the management of severe sepsis and septic shock. Intensive Care Med 2004;30:536-55.

7. Dellinger RP, Levy MM, Carlet JM, Bion J, Parker MM, Jaeschke R, et al. Surviving Sepsis Campaign: International guidelines for the management of severe sepsis and septic shock: 2008. Intensive Care Med 2008;34:17-60.

8. Dellinger RP, Levy MM, Rhodes A, Annane D, Gerlach H, Opal SM, et al. Surviving Sepsis Campaign: International guidelines for the management of severe sepsis and septic shock, 2012. Intensive Care Med 2013;39:165-228. 
9. Skinner SC, Iocono JA, Ballard HO, Turner MD, Ward AN, Davenport DL, et al. Improved survival in venovenous vs venoarterial extracorporeal membrane oxygenation for pediatric noncardiac sepsis patients: A study of the Extracorporeal Life Support Organization registry. J Pediatr Surg 2012;47:63-7.

10. MacLaren G, Butt W, Best D, Donath S. Central extracorporeal membrane oxygenation for a refractory pediatric septic shock. Pediatr Crit Care Med 2011;12:133-6.

11. Dellinger RP, Levy MM, Rhodes A, Annane D, Gerlach H, Opal SM, et al. Surviving Sepsis Campaign: International guidelines for the management of severe sepsis and septic shock: 2012. Crit Care Med 2013;41:580-637.

12. Rambaud J, Guilbert J, Guellec I, Renolleau S. A pilot study comparing two polymethylpentene extracorporeal membrane oxygenators. Perfusion 2013;28:14-20.

13. Leteurtre S, Martinot A, Duhamel A, Proulx F, Grandbastien B, Cotting J, et al. Validation of the paediatric logistic organ dysfunction (PELOD) score: Prospective, observational, multicentre study. Lancet 2003;362:192-7.

14. Richardson DK, Corcoran JD, Escobar GJ, Lee SK. SNAP-II and SNAPPE-II: Simplified newborn illness severity and mortality risk scores. J Pediatr 2001;138:92-100.

15. Gaies MG, Gurney JG, Yen AH, Napoli ML, Gajarski RJ, Ohye RG, et al. Vasoactive-inotropic score as a predictor of morbidity and mortality in infants after cardiopulmonary bypass. Pediatr Crit Care Med 2010;11:234-8.

16. Leteurtre S, Dupré M, Dorkenoo A, Lampin ME, Leclerc F. Assessment of the pediatric index of mortality 2 with the Pao2/Fio2 ratio derived from the Spo2/Fio2 ratio: A prospective pilot study in a French pediatric intensive care unit. Pediatr Crit Care Med 2011;12:e184-6.

17. Bréchot N, Luyt CE, Schmidt M, Leprince P, Trouillet JL, Léger $\mathrm{P}$, et al. Venoarterial extracorporeal membrane oxygenation support for refractory cardiovascular dysfunction during severe bacterial septic shock. Crit Care Med 2013;41:1616-26.

18. Paden ML, Conrad SA, Rycus PT, Thiagarajan RR; ELSO Registry. Extracorporeal life support organization registry report 2012. ASAIO J 2013;59:202-10.

19. McCune S, Short BL, Miller MK, Lotze A, Anderson KD. Extracorporeal membrane oxygenation therapy in neonates with septic shock. J Pediatr Surg 1990;25:479-82.
20. Hocker JR, Simpson PM, Rabalais GP, Stewart DL, Cook LN. Extracorporeal membrane oxygenation and early-onset group B streptococcal sepsis. Pediatrics 1992;89:1-4.

21. Huang CT, Tsai YJ, Tsai PR, Ko WJ. Extracorporeal membrane oxygenation resuscitation in adult patients with refractory septic shock. J Thorac Cardiovasc Surg 2013;146:1041-6.

22. Bartlett RH. Extracorporeal support for septic shock. Pediatr Crit Care Med 2007;8:498-9.

23. Maclaren G, Butt W, Best D, Donath S, Taylor A. Extracorporeal membrane oxygenation for refractory septic shock in children: One institution's experience. Pediatr Crit Care Med 2007;8:447-51.

24. Qureshi FG, Jackson HT, Brown J, Petrosyan M, Rycus PT, Nadler EP, et al. The changing population of the United States and use of extracorporeal membrane oxygenation. J Surg Res 2013;184:572-6.

25. MacLaren G, Cove M, Kofidis T. Central extracorporeal membrane oxygenation for septic shock in an adult with H1N1 influenza. Ann Thorac Surg 2010;90:e34-5.

26. Sivarajan VB, Best D, Brizard CP, Shekerdemian LS, D'Udekem Y, Horton SB, et al. Improved outcomes of paediatric extracorporea support associated with technology change. Interact Cardiovase Thorac Surg 2010;11:400-5.

27. Jansen TC, van Bommel J, Woodward R, Mulder PG, Bakker J. Association between blood lactate levels, sequential organ failure assessment subscores, and 28-day mortality during early and late intensive care unit stay: A retrospective observational study. Crit Care Med 2009;37:2369-74.

28. Nguyen HB, Rivers EP, Knoblich BP, Jacobsen G, Muzzin A, Ressler JA, et al. Early lactate clearance is associated with improved outcome in severe sepsis and septic shock. Crit Care Med 2004;32:1637-42.

29. Mikkelsen ME, Miltiades AN, Gaieski DF, Goyal M, Fuchs BD, Shah CV, et al. Serum lactate is associated with mortality in severe sepsis independent of organ failure and shock. Crit Care Med 2009;37:1670-7.

30. Kim YA, Ha EJ, Jhang WK, Park SJ. Early blood lactate area as a prognostic marker in pediatric septic shock. Intensive Care Med 2013;39:1818-23.

31. Walker CA, Griffith DM, Gray AJ, Datta D, Hay AW. Early lactate clearance in septic patients with elevated lactate levels admitted from the emergency department to intensive care: Time to aim higher? J Crit Care 2013;28:832-37. 